\title{
Supercentenarians in Japan
}

\author{
Yasuhiko Saito \\ Nihon University Kaikan Daini Bekkan, 12-5, Goban-cho, Chiyoda-ku, \\ Tokyo 102-8251, Japan. E-Mail: saito.yasuhiko@nihon-u.ac.jp
}

\begin{abstract}
This chapter provides an overview of two registration systems, the Family Register "Koseki" and the Registry Registration System, which are the basis of age validation in Japan. Data sources for centenarians and supercentenarians are described and the reliability of the information on birth and death is discussed. The chapter explains how we validated the ages of the persons studied and presents trends in the highest ages and the number of supercentenarians in Japan.
\end{abstract}

\section{Introduction}

The number of centenarians in Japan reported by the Ministry of Health, Labor and Welfare in 2003 was 20,561. The number had increased more than 130-fold since 1963, when the then Ministry of Health and Welfare started reporting the number of centenarians. At that time, there were only 153 persons aged 100 and over. The source of these figures and the only publicly available data source for living persons aged 100 and over by single years of age in Japan is the government-produced list of centenarians ("Zenkoku Koureisha Meibo"). This list was used to identify the supercentenarians, defined here as those aged 110 and over, to contribute to the International Database on Longevity (IDL). Japan is one of the very few countries having a sizable number of centenarians and supercentenarians in which we could examine the trends over a long period of time. In this report, we first introduce two registration systems which are the bases of age validation in Japan. We then discuss the data available for centenarians, because these data indicate the quality of data sources for supercentenarians. This discussion is followed by an explanation of how we validated the ages of the persons studied, and how we obtained data 
not available on the list of centenarians published by the Ministry of Health, Labor and Welfare. Finally, trends in both surviving and deceased supercentenarians in Japan, followed by concluding remarks, are presented.

\section{Basis of age validation}

In Japan, the civil registration system is based on the Family Register ("KOSEKI") where all official data related to a given family are recorded, including births and deaths. We have to rely on this registration system in order to validate the age of a person. However, access to the family register has been highly restricted since 1976. Fortunately, there is another registration system, the Resident Registry System, through which it has been, until recently, easier to obtain records for persons of interest for academic research purposes. We discuss each registration system in detail in this section.

\subsection{Family Register "KOSEKI"}

Family Register "KOSEKI" is a family register containing records of all members of a family, and generally includes sex, dates and places of birth, dates of entry to (marriage, adoption, etc.) and removal from (divorce etc.) a family register, names of parents, and relationship to the head of a family. When a member of a family is dead or removed from a given family register by divorce or adoption, the date of events is recorded in the family register, and the record for the member is simply crossed out by lines. As can be seen in the example in Figure 1, the father of the head of the family died in 1910, and his column was crossed out. But the record remained in the family register until a new family register was created by the changes in the Family Registration Law. When new family registers were created by transcribing records from old family registers, those family members who were dead or removed from the old registers were not transcribed to new family registers. Old registers should have been kept for a minimum of 50 years or 80 years, depending on the registration laws. The registers are kept in the municipality office, which has control over the address for a given family register. Japanese citizens are free to choose any registered address that exists in Japan when a head of a given family files for registration. Therefore, there are people using the address of the Imperial Palace or the Diet building as their registered address for their family register in the recent KOSEKI. The same address for the register can be shared 
by any number of Japanese citizens. For example, the domicile of the author's family register was shared by his father and brother.

The family registration system, which covers the whole population of Japan, was established by the family registration law ("KOSEKI HO"). This law was enacted on April 4, 1871, went into effect on February 1, 1872, and has been revised many times (see Table 1, which lists only significant revisions). The first registration was called "JinshinKOSEKI," with the name coming from the animal year for 1872. A family register for a given family was a piece of paper that was bound together with others to make a book. There was no standardized form for the entire country, but the information to be recorded was specified in the law. In Jinshin-KOSEKI, the date of birth was not recorded, but the age at the registration, including number of months, was recorded. Although Jinshin-KOSEKI was the family register, a family register was based on the domicile of a given family, and the unit of registration was the household, which included unrelated individuals living in the same household. Two copies of a family register were prepared. One copy was kept in a local authority, and the other was sent to the central administrative office. Jinshin-KOSEKI was open to the public until 1968, provided the person who requested a copy of a family register, or asked to see a family register, had reasonable grounds. However, because of a record related to a caste-like system, Jinshin-KOSEKI has been sealed in regional branches of the Ministry of Justice since that time.

In 1886, the Family Registration Law was revised and a standardized form of family register was specified. In this revision, a date of birth for all members of a family was required to be in the records, and a penalty was introduced for those who failed to report births, deaths, etc., within a given period of time after the events occurred. A system of removing family registers ("JOSEKI") was also established in this revision, and a family register which is removed from the binding of family registers was called "JOSEKIHYO". If all members of a family were moved to another location or deceased, a family register for the family was removed from the binding of family registers at the origin. However, the removed family registers should be kept for 80 years by law. After 80 years, each municipality is free to discard or keep the registers.

The Family Registration Law was revised again in 1898. With this revision, the Japanese Family System was established, and each family became a unit of registration. A new column was added in the family register for a head of a family (see Figure 1). Usually the role was 


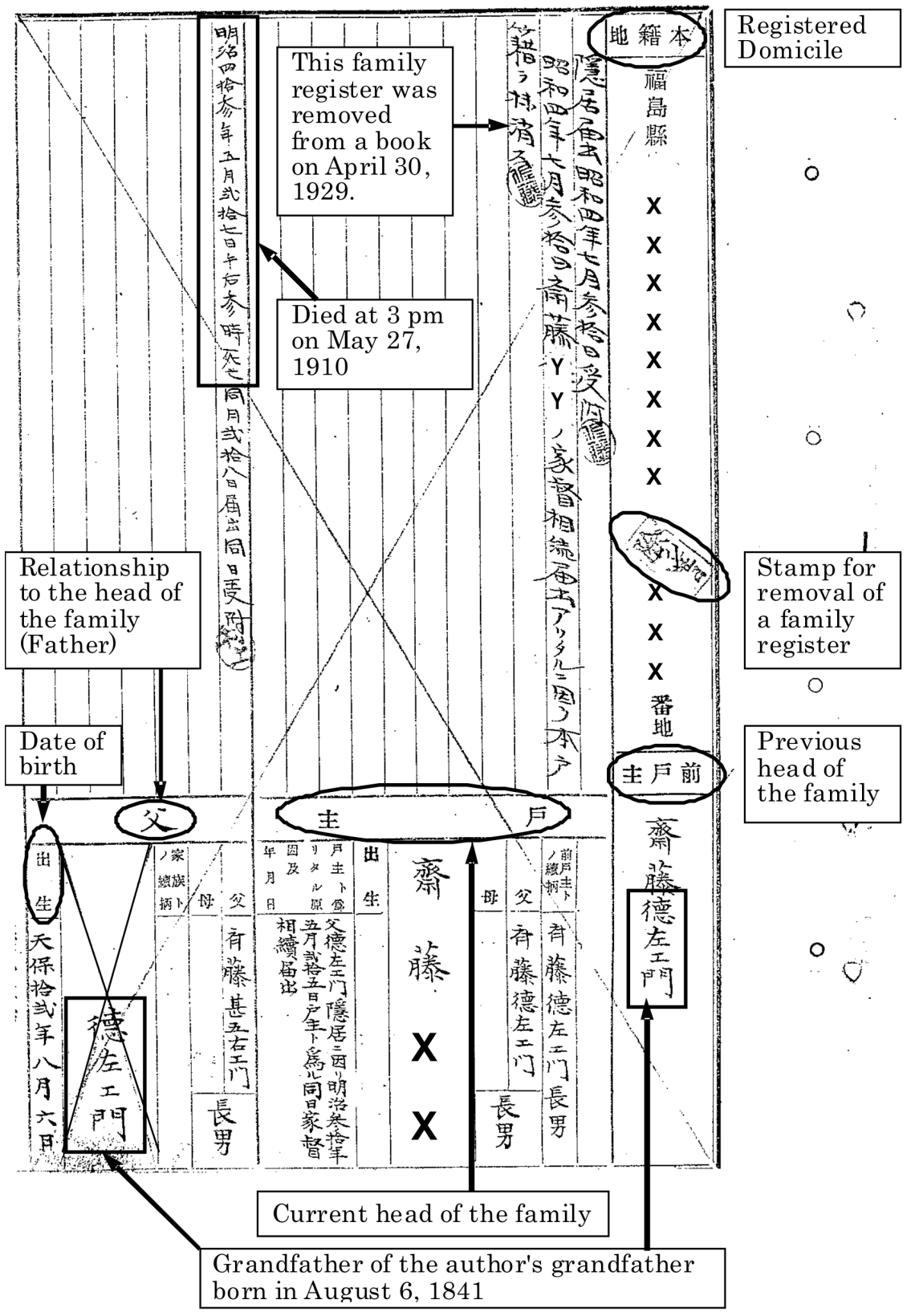

Fig. 1. Example of a family register: 1898 form 
passed on to the first son of a family. A head of a family had authority over all family members, but was also responsible for supporting the family. In this revision, family registers, including old family registers, became open to the public, at least in principle.

The law was also revised in 1914 and in 1947, after World War II. In the 1947 revision of the Family Registration Law, the Japanese Family System was abolished some 50 years after it was established, and the unit of registration became a conjugal union. Information on only two generations at the most was recorded in a given family resister, i.e., parents and their children. Although there is no column for a head of a family in the new form of family register (see Figure 2, for example), the order of family members to be listed was specified. The first member of a family to be listed is either the husband and wife, depending upon what name the family carries. A married couple is allowed to decide which family name is to be carried when they register, but they are not allowed to register under different family names for the husband and the wife. Those family members listed in a family register are not necessarily living in the same household.

Using Figure 3, we would like to illustrate changes in a family register, removal of a family member, and removal of a family register. Let's assume that all family members in Figure 3 were listed in a family register in Jinshin-KOSEKI. Then, if the sister (16) of the head of the family got married, and the younger brother (15) died, their column was crossed out in the family register. With the revision of the law in 1886, the new family register was made without transcribing the information of the sister and the younger brother. The old family register was supposed to be kept for 80 years at the municipality office, which has authority over the registered address. If all the family members were deceased or removed from the family register before 1886, then the family register for this family would be removed from a binding of family registers for an area, and would be kept as JOSEKIHYO for 80 years. The information of those who were registered in Jinshin-KOSEKI, or of those who were born before the 1886 revision, may have been transcribed four times by the time 1947 revision of the law went into effect. If all the family members illustrated in Figure 2 were alive before the 1947 revision of the law, four family registers could have been created from the old family register: one for the father of the head of a family (3), the mother of the head (4), the brother of the head (15), and the sister of the head (16); one for the head of a family (1), the spouse of the head (2), and the first daughter of the head (9); one for the first son of the head (5), the spouse of the first 


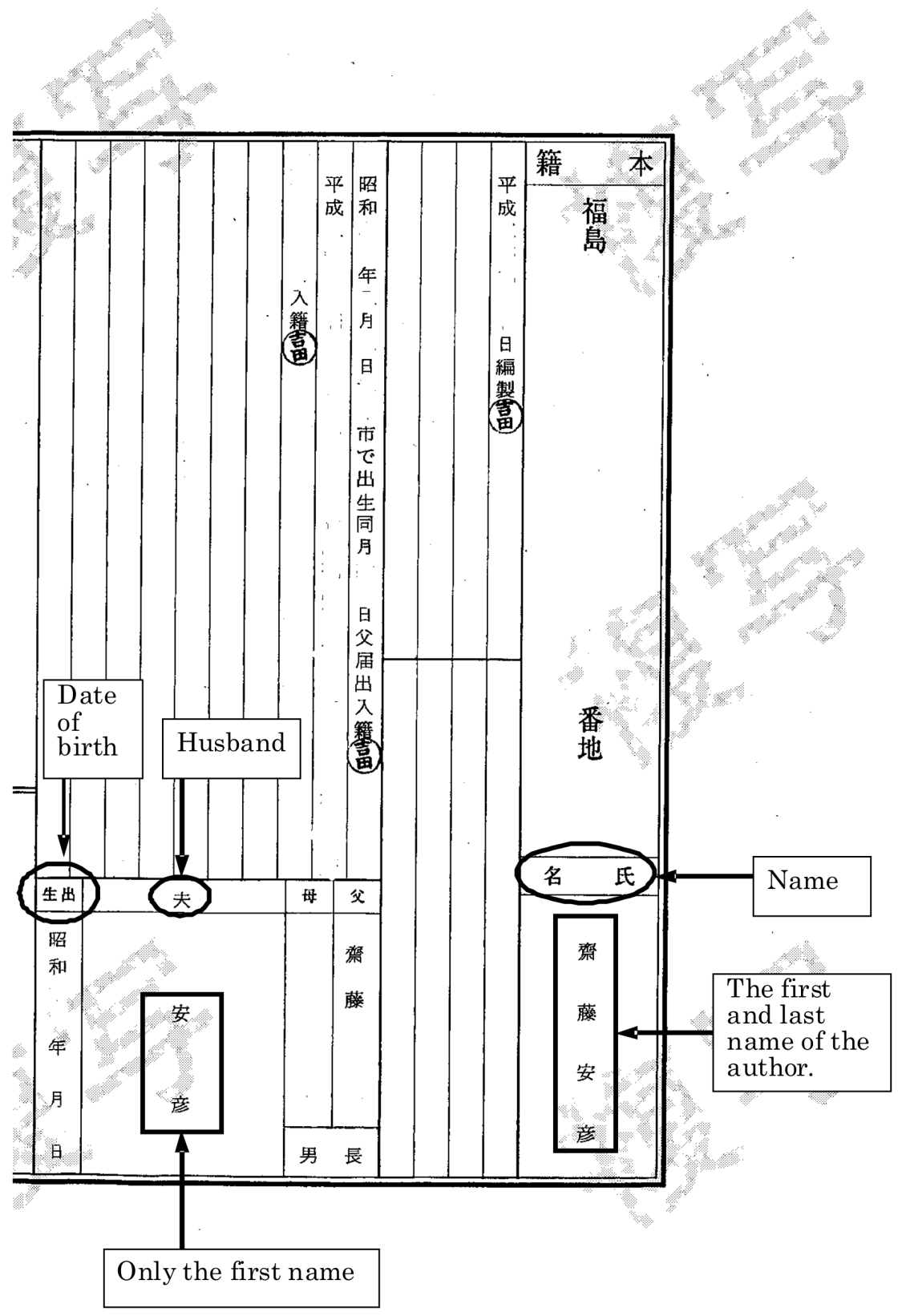

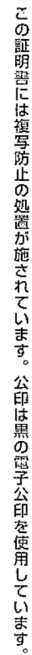

Fig. 2. Example of a Family Register: 1947 Form 
son (6), and the grandchildren of the head, (10), (11), and (12); and, finally, one for the second son of the head (7), the spouse of the second son (8), and the grandchildren of the head, (13) and (14).

Often a family register using the form defined by the 1947 revision of the Family Registration Law is called the current family register ("Genko KOSEKI") because the form has been used since then.

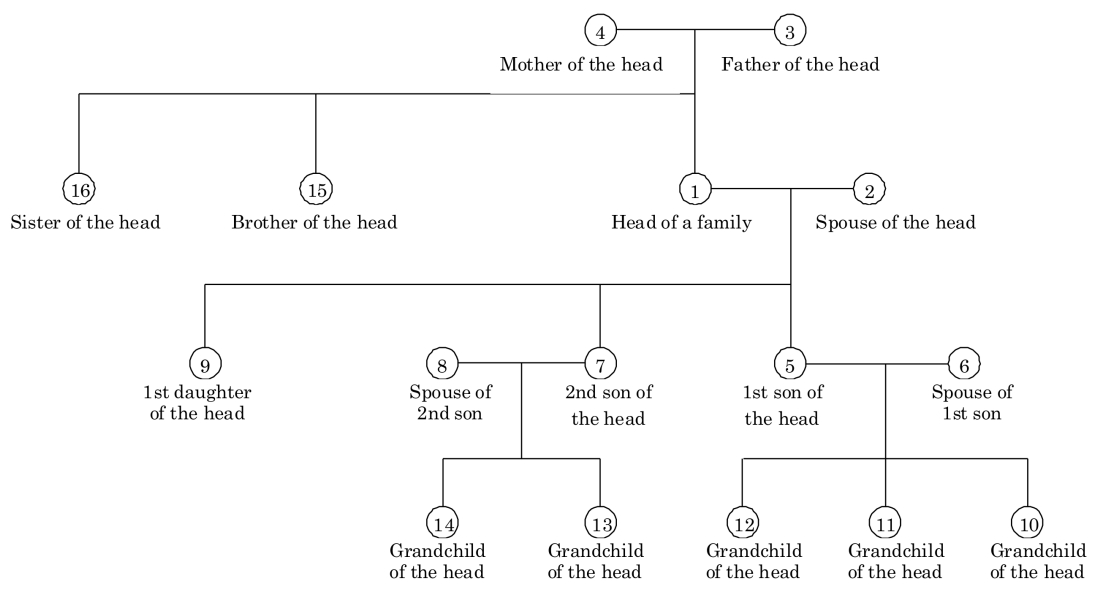

Fig. 3. Illustration of a family tree recorded in KOSEKI before 1947

However, the revision of the Family Registration Law in 1994 allowed municipalities to computerize a family register. Therefore, in those municipalities that had already computerized their family registers, the computerized family register is the current family register, and the previously used family registers are called "Kaisei Gen KOSEKI".

Although Jinshin-KOSEKI was sealed in 1968, as mentioned above, more recent forms of family registers were still available to the public until 1976. With the revision in 1976, access to family registers was restricted.

It is probably worth mentioning what happened to family registers in Okinawa after World War II. Basically, family registers were lost during the war. According to the Okinawa Branch of the Ministry of Justice, the Ryukyu (the name of the kingdom that existed in Okinawa before the Japanese invasion) Government under the U.S. occupation enacted "Koseki Seibi Ho" (law for reconstruction of KOSEKI) on March 1, 1954, and started reconstruction of the family registers based on self-reports by heads of household. The reconstruction of KOSEKI 


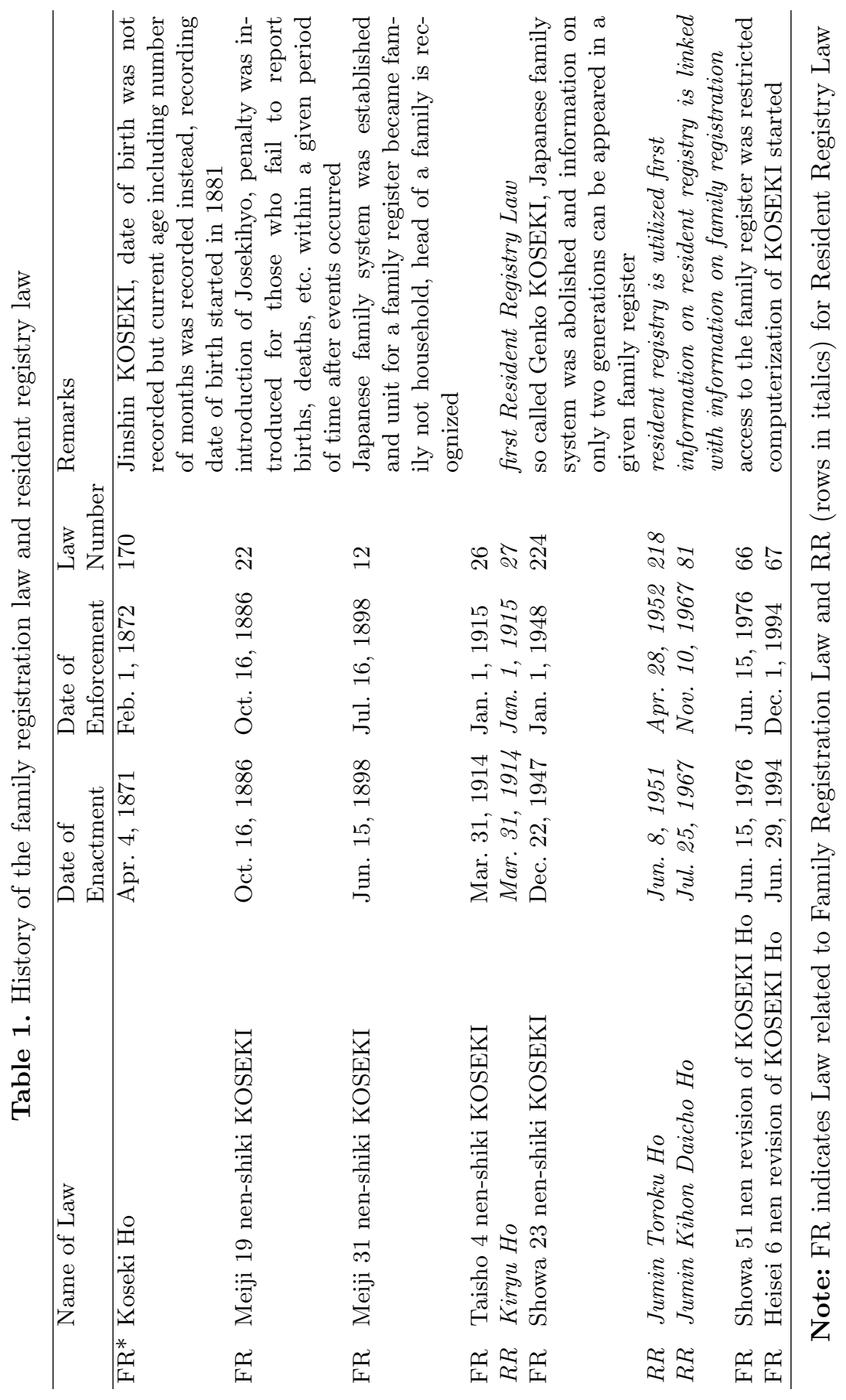


in Okinawa was completed within a few years. Okinawa was returned to Japan in 1972, and reconstructed KOSEKI by the Ryukyu Government were treated as if they were KOSEKI created by the Family Registration Law revised in 1947.

\subsection{Resident Registry}

The Resident Registry System is another civil registration system in Japan, and is based on current residence. Limited demographic information for entire members of a given household was recorded in a resident's card ("Jumin-hyo"), including the address registered in a family register, date of birth, date of death, relationship to the household head, and the previous address of the members immediately before moving into their current residence.

The first Resident Registry Law ("Kiryu Ho"), which was enacted in 1914 and went into effect in 1915, was intended to help maintain a registration system. When the Family Registration Law was enacted, the household was the basic unit for the registration. However, the unit for the registration had changed to the family by the 1989 revision. As the volume of migration increased within Japan, the Family Registration System was inadequate for tracking migrants. The Resident Registry Law was amended as "Jumin Toroku Ho" in 1951, and as "Jumin Kihon Daicho Ho" in 1967. The Resident Registry Law was enacted for purposes of taxation, suffrage, health insurance, pension, and schooling of children. The system carries information on the address of the original registration, and the date of birth from the Family Registration System. The Resident Registry System is based on place of residence, and carries records of persons living in the same household. When events such as births, deaths, marriages, and divorces occur, residents are mandated to report such events at the municipality of their current residence. These changes are reflected in the records of the Family Registration System. Once a person dies or changes residence, their records are generally discarded after five years. This is the duration stipulated by law for which records must be kept. Therefore, generally speaking, it is possible to obtain information on the dates of birth of survivors, and the dates of birth and death of deceased persons for the last five years. The difference between a family register and a resident registry is that information included in a resident registry is current only, and cannot be used to trace family lineage. 


\section{Data sources for centenarians and supercentenarians in Japan}

In Japan, there are currently three data sources for the number of centenarians, and only two data sources for supercentenarians. Both data sources for verifying the ages of supercentenarians are based on the registration system outlined above.

1. Census: The census started in Japan in 1920, and has been conducted on October 1 every five years since then, with the exception of 1945, when it was carried out in 1947 instead. In the census, population numbers are reported by sex and age, which is generally expressed as a single year. However, the highest single year of age reported in the census is 99, while higher ages are grouped as age 100 and above. Therefore, we can only observe the trends in the numbers of people aged 100 and above, as shown in Figure 4. The number of centenarians between 1920 and 1965 changed only slightly, increasing or decreasing within the range of 50 to 250. From 1970 onward, the number increased tremendously, almost doubling every five years (Robine and Saito, 2003). The census data are compared later with another data source for centenarians to examine the quality of data for supercentenarians.

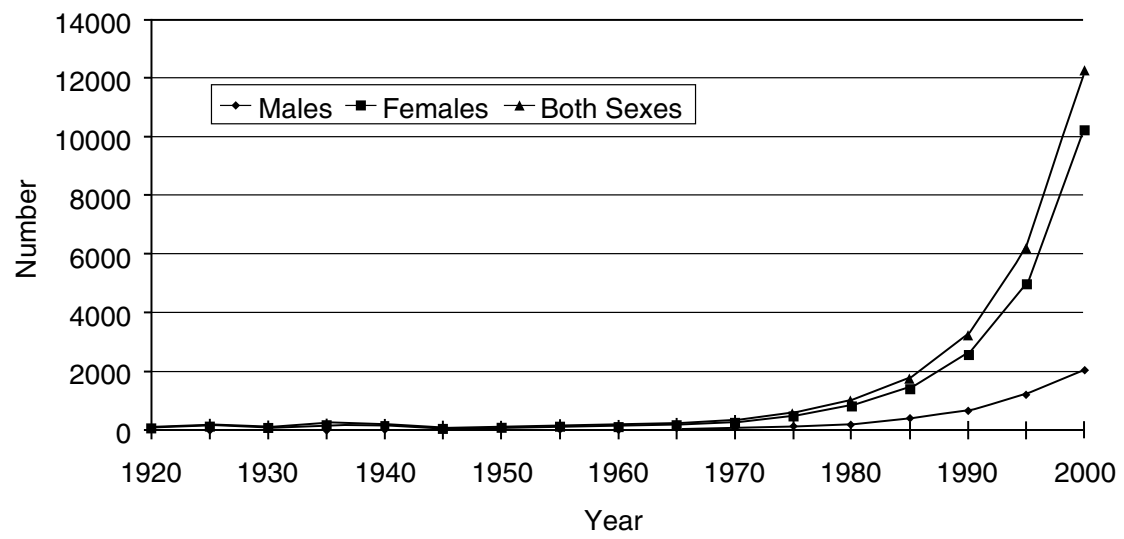

Fig. 4. Number of centenarians: 1920-2000 
2. Vital Statistics: Since 1899, the number of deaths by single years of age and sex has been reported annually by the Ministry of Health, Labor and Welfare. Although we are not able to observe living centenarians or supercentenarians, at least we know how many of them died every year. We can also observe the highest age at death reported each year. By examining the trend in the highest age at death, we could have an indication of trends in the highest age reached by Japanese.

3. List of Centenarians ("Zenkoku Koureisha Meibo"): The then Ministry of Health and Welfare started publishing in 1963 the number of people who would reach, as of September 30 of each year, age 100 and above. The list was complied to celebrate the centenarians on "Elderly Day," which later became a national holiday called "Respect for the Aged Day." Because the number of centenarians started increasing substantially around 1965, the timing of the move to compile a list of centenarians has been particularly useful in helping us to observe changes in the number of centenarians.

Figure 5 shows the numbers of centenarians since 1965 from censuses and the list of centenarians, and the differences between these two sources by percentage of the number of centenarians from the census. The differences in the number of centenarians between the two sources range from $7.7 \%$ in 1980 to $-6.4 \%$ in 2000 . The differences in the numbers before 1985 are almost all positive, indicating that the number of centenarians from censuses exceeded those from the list of centenarians. However, since 1990, the numbers from the list have exceeded census figures. The excess number of centenarians included in the list is more plausible because the list is compiled in early September, although it indicates the number of centenarians as of September 30. Censuses are conducted on October 1, and some people on the list may have died before the census date. It may be hard to prove which source is more accurate. It is worth noting that censuses are selfreported, while the list of centenarians is compiled by municipalities based on official records - although official records may not be perfect, as we shall discuss later.

\section{Validation of date of birth and death}

We have used the list of centenarians to obtain information on supercentenarians since 1963. However, the list provides information only on surviving centenarians, and does not contain information on dates of death for deceased supercentenarians. What we are able to observe from a series of lists of centenarians is that some of the supercentenar- 


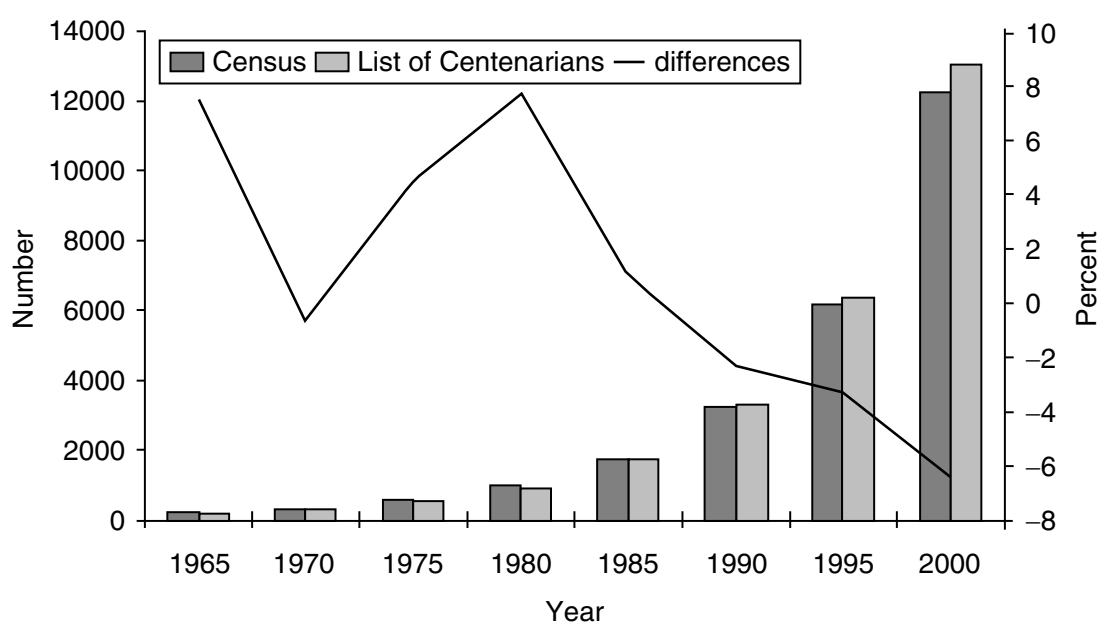

Fig. 5. Number of centenarians in census and the list of centenarians, and difference in percent: 1965-2000

ians' names which had been listed previously disappear from the list over the years. This is an indication that they may have died during a year prior to publication of the list of centenarians for a given year. We also do not know the survival status of those who are on the latest list of centenarians.

When accessing individual records of the Family Registration System and the Resident Registry System in order to obtain information on date of death, two different rules apply. Access to the family registrations is restricted to the members of a given family or lineal descendants of the family. Only they can file requests with municipalities to see and duplicate the records of family members under the Family Registration System. Therefore, we have to ask surviving supercentenarians or family members of deceased supercentenarians to file a request with the municipality for a copy of a family register for a given supercentenarian, and to provide us with the copy. There are two types of certificates that may be requested from a given family register: one shows information on the entire family ("KOSEKI TOHON"), and the other is an abstract of the family register ("KOSEKI SHOHON"). If necessary, a copy of a family register created before 1947 can be requested. The example shown in Figure 1 is the first page of a family register, which is a form specified in the 1898 revision of the Family Registration Law. This 
is probably the most certain way to validate ages of supercentenarians using records from the Family Registration System. This is partly because we are able to observe ages of siblings and other members of the family as well. However, there is no guarantee that supercentenarians or the families of supercentenarians will agree to provide us with such personal information for academic studies.

In contrast, under the Resident Registry System anyone could request duplicates of a particular person's record, "Jumin-hyo" (a certificate of residence) or "Joseki-hyo" (a certificate of deletion), without the consent of that person. Provided the researcher making the request has information on the name, sex, date of birth, and full address of the particular person of interest; as well as the relevant forms and materials, payment for fees, and a plausible reason for wanting access to the certificate, it is possible to obtain personal information. Academic research can be regarded as one such plausible reason for wanting access to the certificates, although the decision on whether to allow access is made by the head of each municipality. If the person still resides at the address specified by the petitioner, a duplicate of a certificate of residence will be sent. If the person moved from the address, a duplicate of a certificate of residence with a new address will be sent. Otherwise, a certificate of deletion with the date of death will be sent.

This is how we obtained information on the dates of death and validated the dates of birth for the supercentenarians listed between 1995 and 2000. The necessary information for requesting duplicates was taken from the list of centenarians. In early 2001, we had requested information on the survival status of those aged 109 and above who were on the list published in September 2000, as well as of those aged 109 and above who were on the list of centenarians in a given year who had disappeared from the following year's list between 1995 and 2000. According to the Resident Registry Law, information on deceased people is supposed to be kept for five years. This is why we requested a copy of a certificate of residence for five years prior to 2001. We included those aged 109 and above because we had to check whether they died after reaching age 110 . There are also two types of certificates of residence that can be requested: one is for the entire household, and the other is for a particular member of a given household. The copy we requested was only for a particular member (supercentenarian) of a given household.

Until recently, it was not too difficult to obtain a copy of a certificate of residence for a member of a given household or an entire household. However, access to the resident registry has been restricted by the en- 
actment of the Privacy Protection Law, which went into effect on April 1,2005 .

\section{Results of the validation}

As shown in Table 2, which was based on the list of centenarians published between 1963 and 2000, we identified 121 centenarians aged 109 and above. Among those 121 centenarians, 27 centenarians were from the list published in 2000, 42 centenarians were from the lists published between 1995 and 1999, and 52 centenarians were from the lists published between 1963 and 1994. In 69 of these cases (from lists between 1995 and 2000), we requested duplicates of the records from municipalities; in six of these cases, our requests were declined. However, for four out of these six cases, information on the dates of death were obtained from news reports. Information on dates of death reported by newspapers is considered to be accurate. We also requested information on the dates of death for two supercentenarians who were not identified by the municipalities. It is possible that the supercentenarians who were not identified may have moved from the address we specified in the request forms. If the information we provided for the supercentenarians did not match exactly the information on file with the municipalities, our requests may have been denied.

Based on copies of the certificates of residence, we found that, for those from the list published in 2000, seven out of 16 persons aged 109 were alive at that age, four were alive at 110, and another four centenarians were deceased at age 109. For one of the persons aged 109, we could not obtain the information. However, this centenarian died at age 109, according to a news report. Among 11 centenarians aged 110 and above, two were alive at the age listed, four were still alive a year later, another four supercentenarians died at the age reported in the list, and one supercentenarian reached another birthday before dying.

From the lists of centenarians published between 1995 and 1999, 23 persons who had reached the age of 109 were identified. Of these, 12 centenarians died at age 109, and seven centenarians died at age 110. Two of our requests were declined, and another two cases were not identified by municipalities. A total of 19 supercentenarians were on the lists between 1995 and 1999. Eight of them died at the age as listed, and another eight supercentenarians reached one more birthday before they died. Requests for information on three supercentenarians were declined by municipalities, but their deaths were all reported in 
Table 2. Summary of supercentenarians in the lists of centenarians and results of age validation

\begin{tabular}{|c|c|c|c|c|c|c|c|c|c|}
\hline \multirow{2}{*}{$\begin{array}{l}\text { Year of } \\
\text { publication }\end{array}$} & \multicolumn{3}{|c|}{$\begin{array}{c}\text { As of } \\
\text { September } 1 \\
2000\end{array}$} & \multicolumn{6}{|c|}{ As of March 31, 2001} \\
\hline & \multirow[t]{2}{*}{ Age } & \multicolumn{2}{|c|}{ Sex } & \multicolumn{2}{|c|}{ Alive at age } & \multicolumn{2}{|c|}{ Deceased at age } & $\begin{array}{l}\text { Request } \\
\text { declined }\end{array}$ & Unknown \\
\hline & & $\mathrm{M}$ & $\mathrm{F}$ & same & +1 & same & +1 & & \\
\hline \multirow[t]{6}{*}{2000} & 113 & & 1 & & 1 & & & & \\
\hline & 112 & & 1 & 1 & & & & & \\
\hline & 111 & 1 & 3 & & 3 & 1 & & & \\
\hline & 110 & & 5 & 1 & & 3 & 1 & & \\
\hline & 109 & 4 & 12 & 7 & 4 & 4 & & $1^{*}$ & \\
\hline & subtotal & 5 & 22 & 9 & 8 & 8 & 1 & 1 & \\
\hline \multirow[t]{7}{*}{ 1995-1999 } & 114 & & 1 & & & 1 & & & \\
\hline & 113 & & 3 & & & 1 & 1 & $1^{*}$ & \\
\hline & 112 & & 4 & & & 2 & 2 & & \\
\hline & 111 & 2 & 3 & & & 2 & 2 & $1^{*}$ & \\
\hline & 110 & 1 & 5 & & & 2 & 3 & $1^{*}$ & \\
\hline & 109 & 4 & 19 & & & 12 & 7 & 2 & 2 \\
\hline & subtotal & 7 & 35 & & & 20 & 15 & 5 & 2 \\
\hline \multirow[t]{11}{*}{ 1963-1994 } & 120 & 1 & & & & & & & \\
\hline & 117 & & 1 & & & & & & \\
\hline & 116 & 1 & 1 & & & & & & \\
\hline & 115 & & 1 & & & & & & \\
\hline & 114 & & 1 & & & & & & \\
\hline & 113 & & 3 & & & & & & \\
\hline & 112 & & 1 & & & & & & \\
\hline & 111 & & 4 & & & & & & \\
\hline & 110 & 1 & 12 & & & & & & \\
\hline & 109 & & 25 & & & & & & \\
\hline & subtotal & 3 & 49 & & & & & & \\
\hline Total & & 15 & 106 & & & & & & \\
\hline
\end{tabular}

Source: "Zenkoku Koureisha Meibo" (List of Centenarians), various years, Ministry of Health, Labor and Welfare

Note: An asterisk ("*") indicates that date of death was reported in the newspaper. 
newspapers. According to the reports, each of these three celebrated one more birthday before they died.

Although we did not request copies of certificates of residence for centenarians aged 109 and over listed between 1963 and 1994, we have summarized the numbers by age and sex at the bottom of Table 2. Only three male supercentenarians were identified, compared with 24 female supercentenarians. In addition, 25 female centenarians were listed as age 109 over the same period.

Table 3. Comparison of number of deaths based on the study and Vital Statistics

\begin{tabular}{cccccc}
\hline \multicolumn{5}{c}{ Female } & \multicolumn{3}{c}{ Male } \\
Year & Age & Vital Stat & This Study & Vital Stat & This Study \\
\hline 1996 & 110 & 1 & 1 & & \\
1997 & 110 & 1 & 0 & 1 & 1 \\
111 & 1 & 1 & 1 & 1 \\
112 & 1 & 1 & 1 & \\
113 & 1 & 1 & & \\
1998 & 110 & 3 & 3 & & \\
111 & 1 & 1 & & \\
112 & 2 & 2 & & \\
113 & 1 & 1 & & \\
114 & 3 & 3 & & \\
1999 & 110 & 1 & 0 & & 1 \\
111 & 2 & 2 & & \\
112 & & & & \\
113 & 1 & 1 & & 1 \\
\hline
\end{tabular}

Sources: 1. "Zenkoku Koureisha Meibo" (List of Centenarians), various years, Ministry of Health, Labor and Welfare; 2. Vital Statistics, various years, Ministry of Health, Labor and Welfare

In Table 3, we compared the number of deaths based on this study's findings, and the number of deaths that appear in the Vital Statistics. We were able to find matches in the Vital Statistics for all deaths 
among supercentenarians identified by this study between 1996 and 2000. Only two out of 27 deaths reported in the Vital Statistics were missing from our study. If we assume the number of deaths reported in the Vital Statistics is correct, our result indicates underreporting of supercentenarian deaths.

\section{Trends in the supercentenarians}

\subsection{Trends in the supercentenarians in Japan from Vital Statistics}

\subsubsection{Trends in the number of deceased supercentenarians}

As shown in Figure 6, the trends in the number of deceased supercentenarians can be examined by using data from the Vital Statistics since 1899. What is surprising about the data shown in Figure 6 is the very large number of supercentenarian deaths in the early half of the 20th century, compared to the number in the latter half of the 20th century, when living conditions were much better and medical technologies were much more advanced. The number of supercentenarian deaths was 28 in 1916, and this is the highest to date. There were periods of no reported supercentenarian deaths in the 1950 s to 1970 s. In the 1990 s, we can observe an upward trend in the number of deaths of supercentenarians.

\subsubsection{Trends in the highest age at death}

Jeanne Calment of France lived 122 years and 164 days. So far, she is the longest-lived person in the world whose age has been validated (Allard, Lèbre, and Robine, 1998). The highest age at death for Japan is shown in Figure 7. In Japanese Vital Statistics, we find 13 persons whose reported age at death exceeds 122 years old between 1930 and 1950. The highest age at death recorded in the Vital Statistics in Japan is 125 , and was reported in 1943. As Figure 7 illustrates, the highest age at death showed an upward trend from 1899 to 1930, and plateaued at around 120 in the 1930s and 1940s. After the 1950s, the highest age at death ranges between 100 and 115, with very few exceptions. One exception is the case of Shigechiyo Izumi, in 1986. The highest ages at death by sex fluctuate widely, but, without outliers, there seems to be increasing trend in the highest age at death for both sexes. A study of the highest and tenth-highest ages at death also suggests an upward trend in the highest ages at death (Robine and Saito, 2003). 


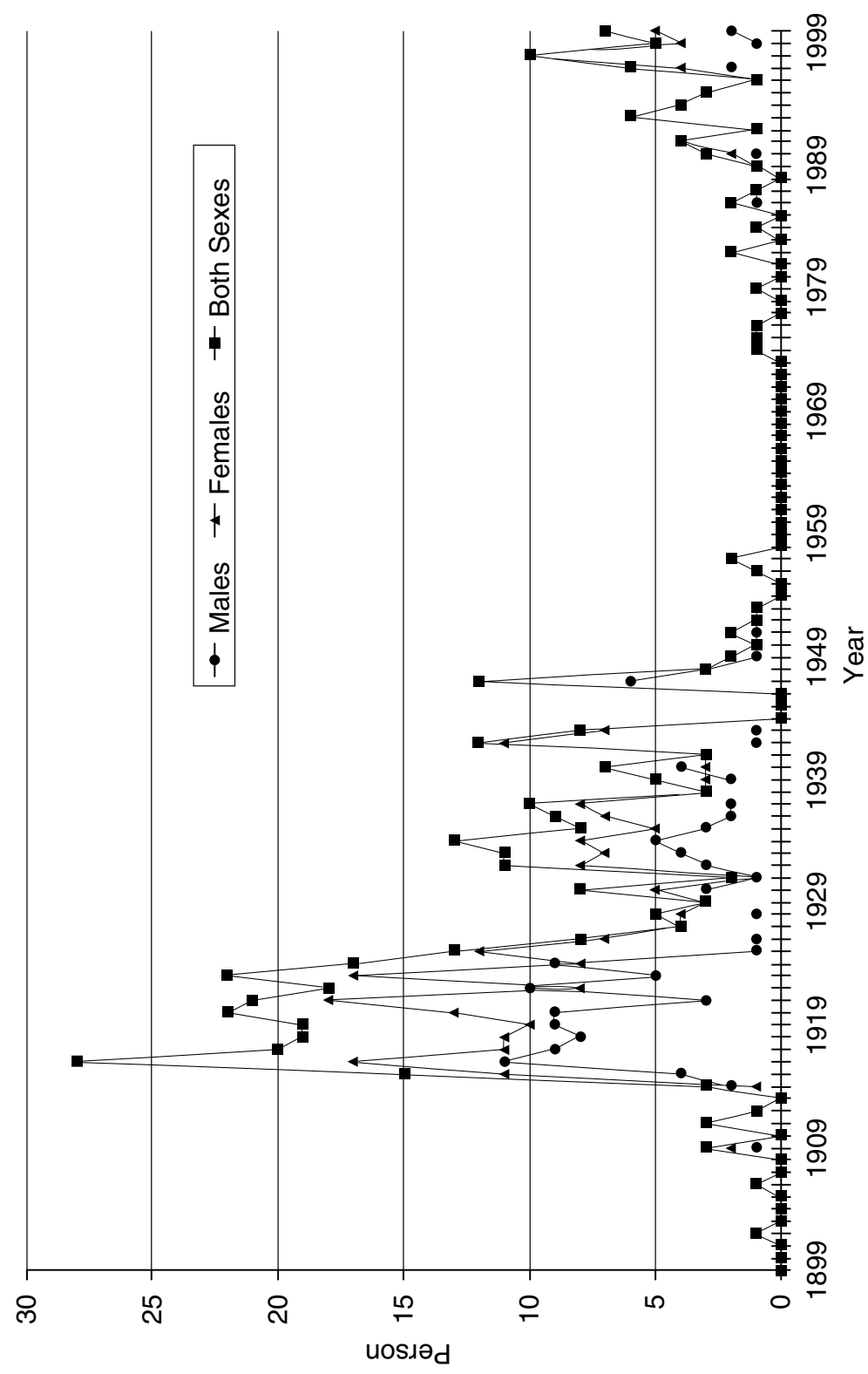




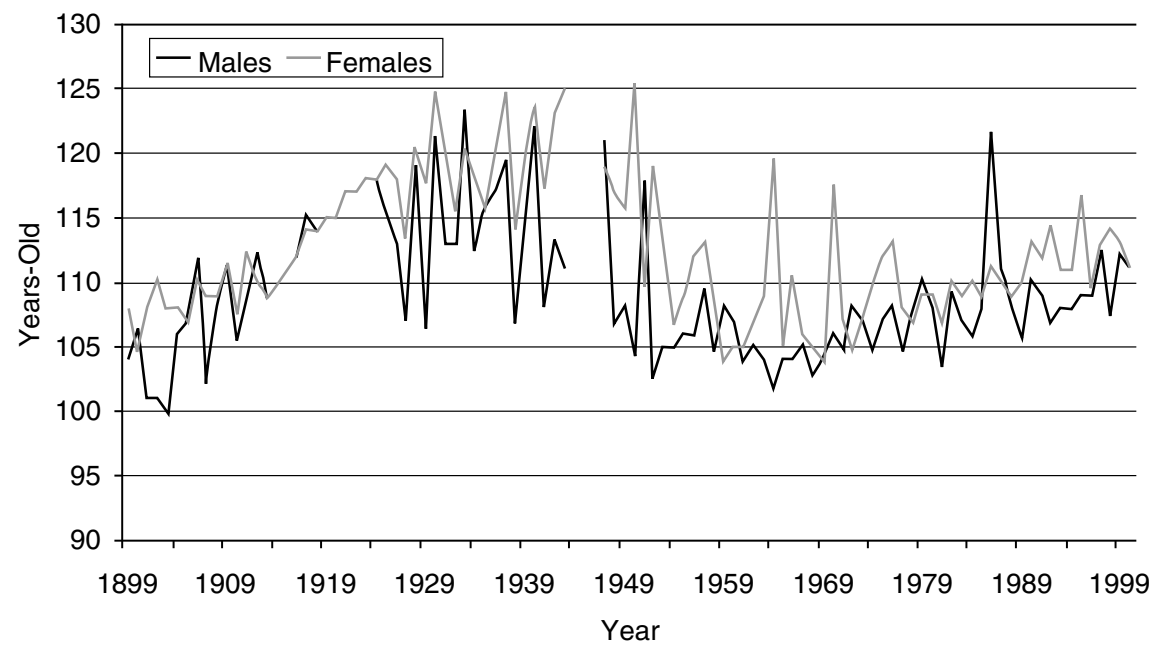

Fig. 7. Highest reported age at death by sex: $1899-2000$

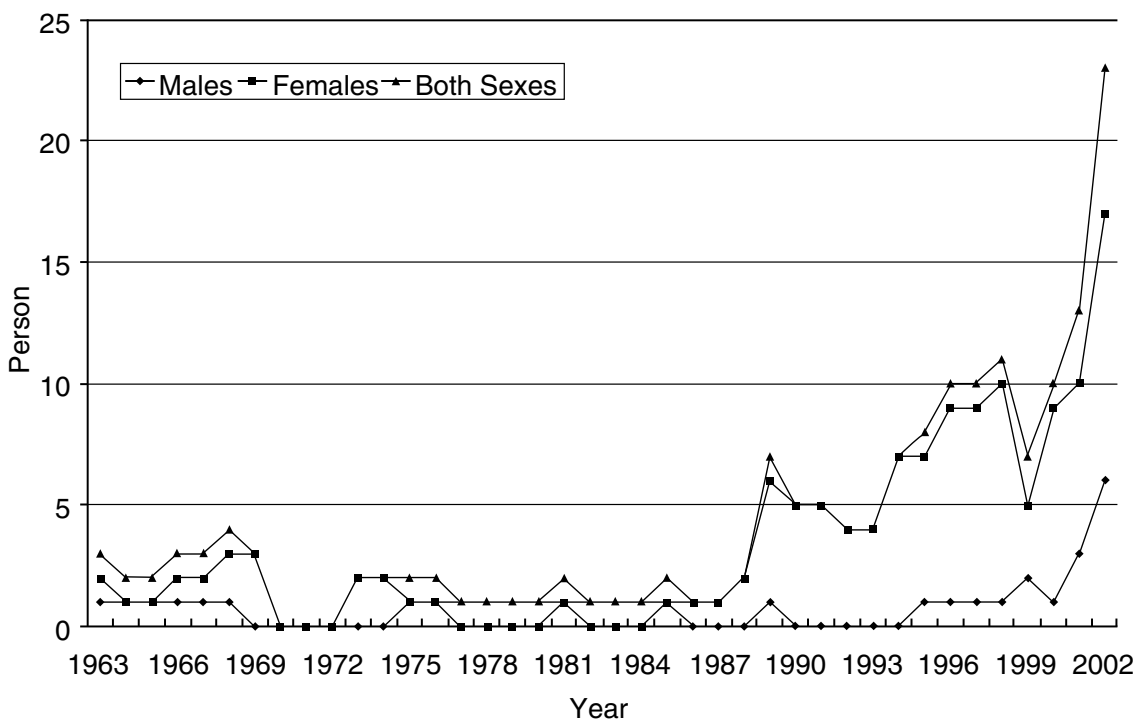

Fig. 8. Number of supercentenarians in Japan for both sexes and by sex: 1963-2003 


\subsubsection{Trends in the age of the oldest living person}

The age of the oldest person alive as of September 30 each year can be also followed since 1963 using the list of centenarians, as shown in Figure 9. Although the increase in the age of the oldest person is small as a trend, there seems to be a slight but steady upward trend in the age since 1970, excepting the case of Izumi.

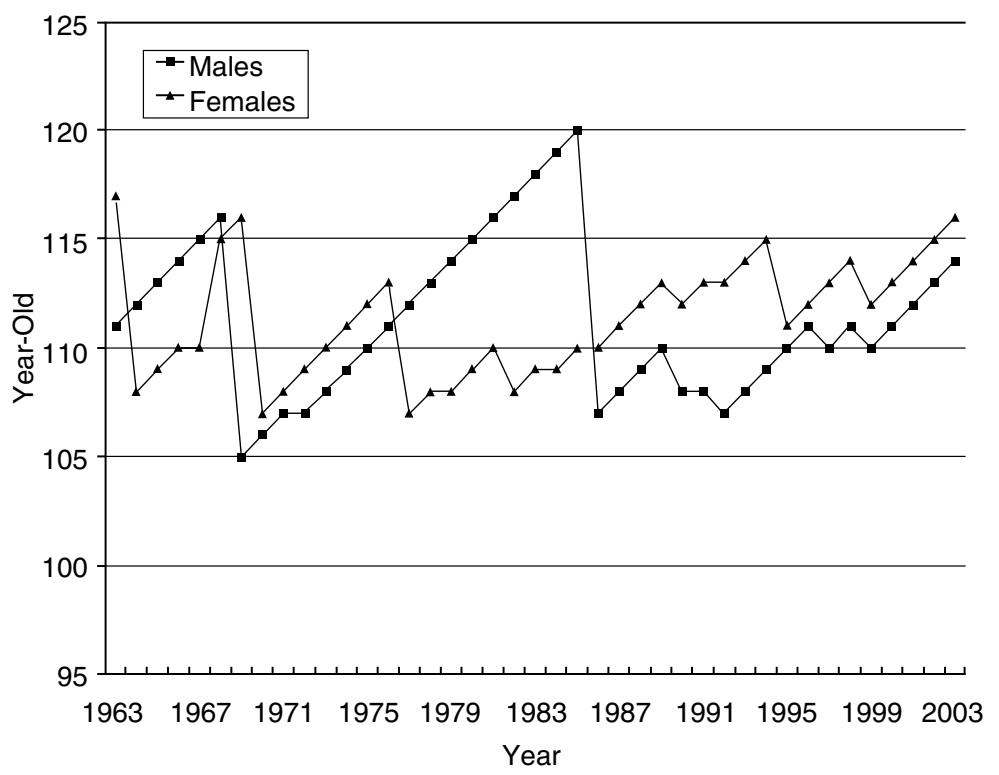

Fig. 9. Reported age of the oldest person alive by sex: 1963-2003

\section{Reliability of information on age and date of birth}

In order to validate ages for supercentenarians in 1963, for example, when the list of centenarians was first published, we have to be certain that records in the system for 1853, at the latest, are accurate. Unfortunately, this was almost 20 years before the first national registration was compiled.

We have to be aware of two things when we use the records from the Family Registration System to validate ages of supercentenarians. One is how the system operated in its early years. As Kitou (1997) points out, it took some time for the system to become complete and accurate. 
The enactment in 1886 of a penalty for failing to report events such as births and deaths within a certain designated time period suggests ubiquitous misreporting of such events before 1886. This, of course, does not mean that all records in the system are incorrect before 1886 . We should, however, use the records registered in the early years of the system with caution.

The second issue is how a person's age was reported for those who had already been born in 1872. In Jinshin-Koseki, only self-reported ages were registered. Therefore, there was a possibility of incorrect ages being unwittingly reported at the time of the first national registration. This could be one of the reasons why in Japan there are many supercentenarians who died in the 1930s and 1940s. We must also be aware that those aged 110 and above before 1982 had already been born at the time of the first national registration. We will discuss further possible causes of age misreporting in this section.

\subsection{Possible causes of age misreporting in the Family Registration System}

Self-reported ages at the first national registration might have been incorrect in some cases, as we mentioned earlier. Although this may not affect our contribution to IDL, this may help understand why there were such a large number of deceased supercentenarians in the 1930s and 1940s, as shown in Figure 6. Of course, we don't know whether those reported ages at death were incorrect. But if it does turn out that these reported ages at death were indeed incorrect, the age misreporting may have happened partly because animal years had been used to count people's ages in Japan at the time of the first national registration. The Western calendar system did not exist in Japan before 1872. The animal year system has a 12-year cycle, and if anyone counts one cycle off of the actual animal year of birth, the person could be 12 years younger or older. We only consider this possibility here for those who may have reported an age that was older than the actual age.

Let's assume that the oldest age that could have been achieved by both sexes in the early half of 20th century is 105 years old. Then consider cohorts of person aged 105 in 1930 and 1950. As shown in Figure 10, they were 27 years old and 47 years old in 1872. At a time when life expectancy was less than 40 years, a person who was 30 years old might not differ much from a person aged 40 or 50 . If some members of cohorts born between 1825 and 1845 who survived to age 105 made mistakes in reporting their ages by one or two cycles of animal years, then they may have appeared to have achieved ages of between 117 
and 129 sometime between 1930 and 1950. This is just a conjecture, but could explain the upward trends in the highest age at death between 1900 and 1930, and the very high ages at death between 1930 and 1950.

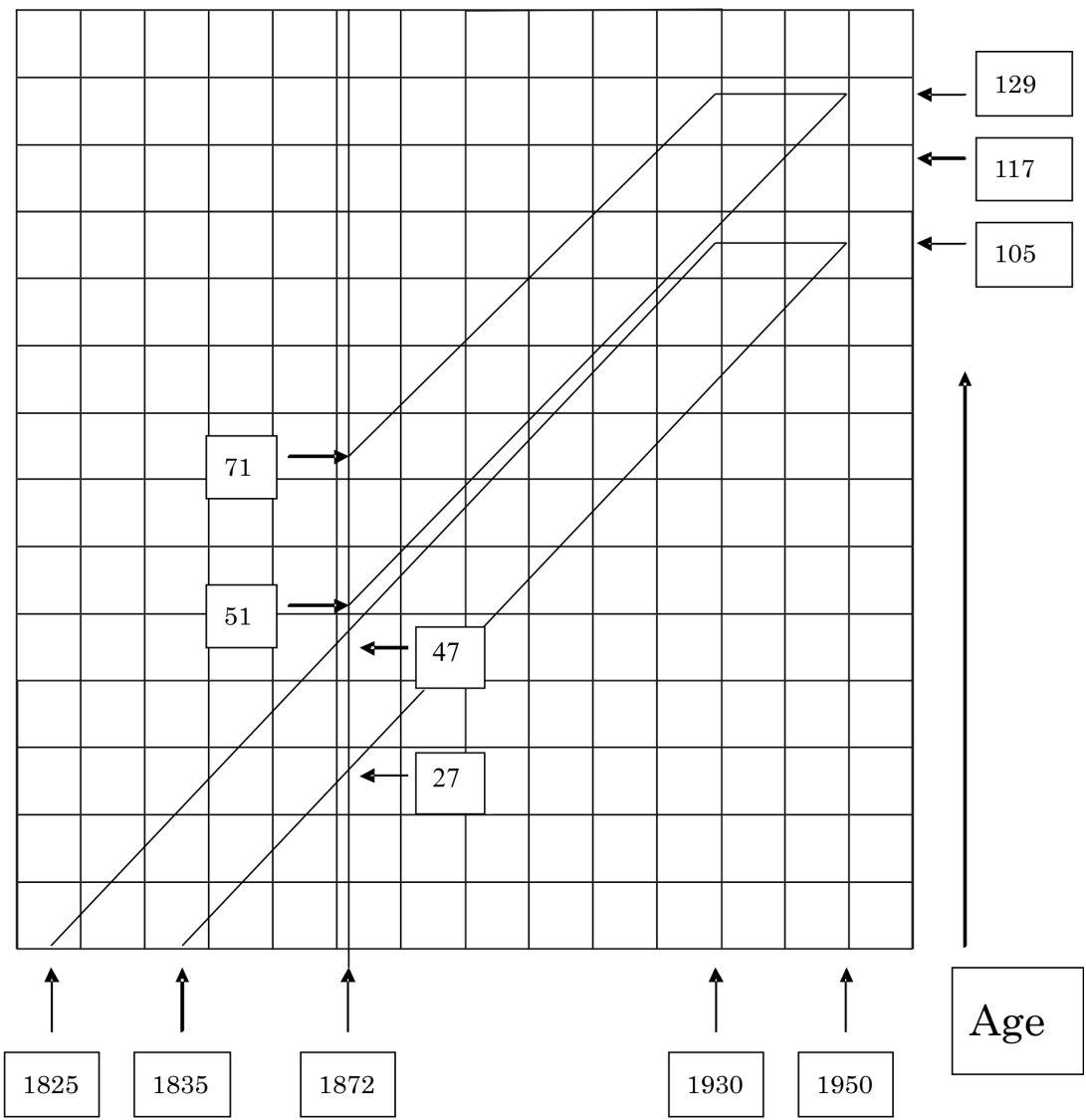

\section{Year}

Fig. 10. Depiction of age misreporting 
Age might have not been important for a lay person then. There was no age-based system at the time, and the school system did not start until 1872. Moreover, during the early years of the school system, enrollment rates were very low. For example, the enrollment rate in 1872 was $40 \%$ for boys and just $15 \%$ for girls. Only after a law regulating the elementary school system was enacted in 1886 did enrollment rates start to increase, reaching $92 \%$ in 1902 (Umihara, 1979).

\subsection{Reliability of information on dates of birth}

In order to check the reliability of dates of birth reported in the Family Registration System, it is worth examining possible causes of age misreporting. There are a couple of possible causes of the misreporting of dates of birth in the Family Registration System. Most of them seemed to happen unwittingly, as mentioned by Matsuzaki (1988).

First, there were cases of dates of birth being recorded in the Family Registration System that were simply incorrect due to errors in the transcription of records from an old register to a new register, or between the registers of two different families. The former tended to happen during the update of the registration, and the latter often happened in the cases of those who married and transferred to a spouse's family register. Since there was no computer to keep all the records, each record of family registers had to be transcribed by hand when there were changes in the records. Matsuzaki (1988) reported an error resulting from transcription for a particular supercentenarian in which the age of the person's elder sister was transcribed by mistake when the person married and moved her records from her family's register to her husband's family register. These types of errors can be found by examining older family registers or family registers that were removed (JOSEKIHYO). Matsuzaki conducted a survey on centenarians in early 1970s (1988). The survey revealed that $5 \%$ of 117 centenarians studied were not centenarians. He also studied seven centenarians aged 109 and above in the mid-1980s. He found that only two out of seven were, in fact, the age that had been reported.

Second, there was a custom in Kagoshima prefecture of Kyusyu of using the registration of a deceased first child for its younger siblings, as reported by Matsuzaki (1988). This is a very serious problem for age validation. We do not have any way to disprove age in such cases. The age given for a person registered as an elder sibling could be easily five to ten years older than his or her actual age. As Matsuzaki (1988) mentioned, such a custom lasted until the mid-Meiji era (around 1890). 
Therefore, we need to pay attention to the dates of birth for those who were born in Kagoshima before 1890 .

\section{Concluding remarks}

Just how reliable is information on dates of birth? That is the question we must try to answer. We discussed possible causes of unreliable reports on dates of birth. Judging from these studies, information on dates of birth seems reliable after around 1885. Those who were born in 1885 can be 110 after 1995. It is from this year onwards that we are requesting information on dates of death.

Over the last few years, it has become very difficult to study supercentenarians and obtain their information. The list of centenarians was the basis for all information we obtained. However, the list was not published by the Ministry of Health, Labor and Welfare as a volume anymore. Both in 2004 and 2005, names of only one hundred oldest Japanese were reported by the Ministry on their home page. Information on those who want to be anonymous was listed on the home page without their names. In 2006, among those aged 109 and above, only those who agreed to be on the list were reported on the home page. These changes can be at least partly attributed to the Privacy Protection Law, which went into effect on April 1, 2005.

\section{Acknowledgement}

This study was supported by Nihon University Population Research Institute and MEXT.ACADEMIC FRONTIER (2006-2010). The author greatly appreciates the support.

\section{References}

Allard, M., Lèbre, V. and Robine, J.M. (1998). Jeanne Calment: from Van Gogh's time to ours, 122 extraordinary years. New York, W. H. Freeman and Company.

Kitou, H. (1997). Meijiotaishoki jinko tokei ni okeru shussho. Jyochi Keizai Ronshu, 43(1):41-65.

Matsuzaki, T. (1988). "Nippon-jin no chouju youin to choujusha no kentou" (Factors related to Japanese longevity and study of Japanese elderly), in S. Hishinuma, Y. Kagawa and M. Yamaguchi (eds.) Nippon-jin ha naze nagaiki suruka (Why does Japanese live longer?), pp. 105-129. Tokyo: Doubun shoin.

Ministry of Health and Welfare (1899-1998). Vital Statistics. Annual issue since 1899. 
Ministry of Health and Welfare (1963-2000). Zenkoku koureisha meibo (A list of centenarians in Japan).

Robine, J.M. and Saito, Y. (2003). Survival beyond age 100: Acceleration of the evolutions in Japan. Population and Development Review, 29:208-228.

Statistics Bureau (Various years). Census of Japan.

Umihara, T. (1979). Gakkou (School). Tokyo, Kondo Shuppan Sha. 